\title{
Integral characteristics of optical spectra, as a new class of descriptors for complex molecular systems
}

\author{
(C) Mikhail Yu. Dolomatov, ${ }^{1,2 *}$ Ella A. Kovaleva, ${ }^{2+}$ Kamil F. Latypov, ${ }^{1}$ \\ Milana M. Dolomatova, ${ }^{1,2+}$ Natalia Kh. Paymurzina, ${ }^{1,2}$ and Gulnara U. Yarmuhametova ${ }^{2}$ \\ ${ }^{1}$ Institute of Physics and Technology of Bashkir State University. Zaki Validi St., 32. Ufa, 450074. \\ Bashkortostan Republic. Russia.Phone: +7 (917) 453-85-16.E-mail: milana.1992@mail.ru \\ ${ }^{2}$ Ufa State Petroleum Technological University. Kosmonavtov St., 1.Ufa, 450062. \\ Bashkortostan Republic. Russia
}

\begin{abstract}
*Supervising author; ${ }^{+}$Corresponding author Keywords: descriptors, structure-properties, spectrum-properties, electronic structure, molecules, molecular systems, biological fluids, hydrocarbon mixtures.
\end{abstract}

\begin{abstract}
The authors summarized the results on the study of the relationship of physicochemical properties with spectral integral characteristics of complex molecular systems: integral absorption, reflection coefficients, integral oscillator forces, color characteristics, integral autocorrelation functions, signal convolutions defined in the visible or UV spectral regions.

It is shown that these integral characteristics are numerical parameters that adequately convey the physicochemical and electronic properties of molecules and their mixtures, so these values can be used as descriptors. Since electronic spectra are unique characteristics of a substance, these descriptors have a high discriminating ability. The classification of such descriptors is given. These values differ from physicochemical descriptors such as absorption maxima, since their determination requires information on the spectrum of these systems without isolating individual bands and maxima using the Fourier transform. In contrast to conventional physicochemical and quantum mechanical descriptors, the proposed descriptors can be applied to the study of multicomponent systems with unknown structure and composition. This makes it possible to use these values to determine the physicochemical properties and averaged over the composition of the electronic characteristics of a substance, such as petroleum distillates, petroleum, biological fluids, and similar mixtures. The paper provides relevant examples, confirmed by statistical data processing. The obtained patterns should be defined as the patterns "spectrum-property" by analogy with the patterns "structureproperty", known in organic chemistry and chemical informatics. The consistency of the developed approach is shown, and a quantum-chemical interpretation of these laws is given. Based on the established spectrumproperty dependencies, analytical methods can be developed for determining the amount of complex hydrocarbon systems, such as oil and their products, gas condensates, products of high-temperature pyrolysis of organic substances, etc. The established patterns can be applied to determine the ionization potentials and electron affinity of molecules, as well as in medical diagnostics, oil refining, petrochemistry, oil field development technology, and other fields of science and nanotechnology.
\end{abstract}

\section{References}

[1] Alexander Mikhailovich Butlerov. Moscow: Publication of the Moscow Society of Naturalists, ed. N.D. Zelinsky. 1949. Ch.3. P.87-118. (russian)

[2] I.I. Baskin, T.I. Madzhidov, A.A. Varnek. Introduction to chemoinformatics: study guide. Part 3. "Modeling" Structure-Property ". 2015. 304p. (russian)

[3] N.F. Stepanov. Quantum mechanics and quantum chemistry. Moscow: World. 2001. 519p. (russian)

[4] I.V. Stankevich, N.S. Zefirov. Topological indices in organic chemistry. Successes chemistry. 1988. Vol. 55. No.3. P.337-366. (russian)

[5] M.A. Elyashevich. Atomic and molecular spectroscopy. $2^{\text {nd }}$ ed. Moscow: Editorial URSS. 2001. 896p. (russian)

[6] V. Schmidt. Optical spectroscopy for chemists and biologists. Moscow: Technosphere. 2007. P.189-194. (russian)

[7] M.Yu. Dolomatov. The use of electron spectroscopy in the physical chemistry of multicomponent stochastic mixtures and complex molecular systems. Ufa: CSTI. 1989. 47p. (russian) 
Full Paper M.Yu. Dolomatov, E.A. Kovaleva, K.F. Latypov, M.M. Dolomatova, N.Kh. Paymurzina, and G.U. Yarmuhametova

[8] M.Yu. Dolomatov. Some physico-chemical aspects of predicting the properties of multicomponent systems under conditions of extreme effects. JRCC named after DI. Mendeleev. 1991. Vol.35. No.5. P.632-638. (russian)

[9] M.Yu. Dolomatov. Physical and chemical bases of new research methods for complex multicomponent systems. Prospects for practical use. Moscow: CCRIITER NEftekhim. 1991. 72p. (russian)

[10] M.Yu. Dolomatov. The use of electronic phenomenological spectroscopy for the identification and study of complex organic systems. Chemistry and technology of fuels and oils. 1995. No.1. P.29-32. (russian)

[11] M.Yu. Dolomatov. Chemical physics of multicomponent organic systems. Ufa: Bashkir Scientific Research Institute of Petroleum Refining. 2000. 123p. (russian)

[12] M.Yu. Dolomatov. Fragments of the theory of real matter. Moscow: Chemistry. 2005. 208p. (russian)

[13] N.V. Kalashchenko, M.Yu. Dolomatov, S.V. Dezortsev. Electronic phenomenological spectroscopy of human blood in health and disease. Theoretical and practical aspects. Moscow: Inter. 2010. 256p. (russian)

[14] M.Yu. Dolomatov, G.R. Mukaeva, D.O. Shulyakovskaya. Electron phenomenological spectroscopy and its application in investigating complex substances in chemistry, nanotechnology and medicine. Journal of Materials Science and Engineering B. 2013. Vol.3. No.3. P.183-199.

[15] M.Yu. Dolomatov. The method of determining the ionization potentials and the electron affinity of atoms and molecules by electron spectroscopy. Journal of Applied Spectroscopy. 1992. Vol.56. No.4. P.570-574. (russian)

[16] M.Yu. Dolomatov. Spectroscopic method for determining the activation energy of a viscous flow of mixturees of high molecular weight organic compounds. Oil refining and petrochemistry. 1990. No.10. P.38-41. (russian)

[17] M.Yu. Dolomatov, Z.F. Kuzmina, S.P. Lomakin, and L.M. Hashper. Determination of the coking behavior of mixtures of high-molecular-weight organic compounds. Chemistry and technology of fuel and oils. 1991. No.9. P.29-30. (russian)

[18] M.Yu. Dolomatov, L.M. Khashper, S.P. Lomakin. Express determination of the relative density of oil fractions. Chemistry and technology of fuel and oils. 1991. No.10. P.32-34. (russian)

[19] M.Yu. Dolomatov, L.M. Hashper, Z.F. Kuzmina. Spectroscopic method for determining the average molecular weight. Chemistry and technology of fuel and oils. 1991. No.7. P.34-35. (russian)

[20] S.V. Dezortsev, M.Yu. Dolomatov, N.V. Kalashchenko, S.N. Ozhgihin, G.U. Kuchukova, M.M. Asabina. Investigation of human biological fluids in health and pathology using electronic absorption spectra. Bulletin of new medical technologies. 2006. Vol.13. No.3. P.159-166. (russian)

[21] M.Yu. Dolomatov, N.V. Kalashchenko, S.V. Desortcev, T.R. Araslanov. Spectroscopic phenomenologycal estimation of the functional state of human organism in rate and pathology. International Journal of Clinical Medicine. 2011. Vol.2. No.2. P.79-81.

[22] N.V. Kalashchenko, M.Y. Dolomatov, S.V. Dezortsev, E.A. Popova, R.R. Kurmankaeva. Normal and pathological color characteristics of human blood components. Journal of Applied Spectroscopy. 2006. Vol.73. No.2. P.245-250.

[23] S.V. Dezortsev, N.V. Kalashchenko, S.N. Ozhtikhin, G.U. Kuchukova, M.M. Asabina. Features of the integral characteristics of electronic blood spectra of donors and patients. Questions of biological, medical and pharmaceutical chemistry. 2007. No.4. P.27-30. (russian)

[24] M.Yu. Dolomatov, T.R. Araslanov, N.V. Kalashchenko, S.V. Dezortsev. Integral quantum parameters of human blood as a measure of information about various diseases. Biomedical electronics. 2012. No.5. P.88-95. (russian)

[25] N.V. Kalashchenko, Sh.M. Safin, M.Yu. Dolomatov, T.R. Araslanov. Phenomenological integral quantum parameters of human blood plasma in brain tumors. Medical Bulletin of Bashkortostan. 2012. Vol.7. No.6. P.7-9. (russian)

[26] M.Yu. Dolomatov, D.O. Shulyakovskaya, G.U. Yarmukhametova, G.R. Mukaeva. Evaluation of the physico-chemical properties of hydrocarbon systems by correlations of the spectrum-properties and color-properties. Chemistry and technology of fuels and oils. 2013. No.3. P.52-56. (russian)

[27] M.Yu. Dolomatov, D.O. Shulyakovskaya, G.R. Mukaeva, G.U. Jarmuhametova, K.F. Latypov. Simple characteristics estimation methods of material and molecule electronic structure. Journal of Materials Science and Engineering B. 2012. No.4. P.261-268.

[28] M.Yu. Dolomatov, E.A. Kovaleva. New molecular descriptor of the structure-property model for evaluating the ionization potentials of naphtho and anthraquinones. Journal of Structural Chemistry. 2015. Vol.56. No.5. P.887-893. (russian)

[29] V.I. Tikhonov. Statistical radiophysics. Moscow: Radio and communication. 1982. 625p. (russian) 
INTEGRAL CHARACTERISTICS OF OPTICAL SPECTRA, AS A NEW CLASS OF DESCRIPTORS...

[30] E.A. Kovaleva, M.Yu. Dolomatov. Autocorrelation analysis of the absorptions of electromagnetic radiation by molecules of polycyclic compounds in the petahertz region. Electromagnetic waves and electronic systems. 2016. No.9. P.20-24. (russian)

[31] K.F. Latypov, M.Yu. Dolomatov. Determination of ionization potential of heterocyclic molecules using optical absorption spectra of electromagnetic radiation in the visible and UV region. Photonics. 2017. No.4. P.78-82. (russian)

[32] M.Yu. Dolomatov, N.H. Paymurzina, and E.A. Kovaleva. Evaluation of donor-acceptor properties of polycyclic hydrocarbon molecules by the integral autocorrelation characteristics of the optical spectra. Butlerov Communications. 2018. Vol.53. No.2. P.28-37. DOI: 10.37952/ROI-jbc-01/18-53-2-28

[33] M.Yu. Dolomatov, K.F. Latypov, and R.Z. Bahtizin. The donor-acceptor properties estimation of oxygen-containing compounds and band-gap energy for anthraquinone nanoclusters with integral characteristics of signals optical absorption spectra. Butlerov Communications. 2018. Vol.54. No.5. P.32-39. DOI: 10.37952/ROI-jbc-01/18-54-5-32

[34] C. Sinclair, S. Roy, Battle, R. David, Rigg, Bryan, Smith, J. Kenneth, MacDonald, Roderick, Nobbs, H. James, MacDonald, V. Lindsay, Hill, R. Adrian. Color in industry. Translation from English [2nd ed.] I.V. Penovoy, P.P. Novoseltsev, ed. F.Y. Telegin. Moscow: Logos. 2002. 579p.

[35] M.Yu. Dolomatov, O.T. Kydyrgychova, L.A. Dolomatova, V.V. Kartasheva. Color characteristics of hydrocarbon petrochemical systems. Journal of Applied Spectroscopy. 2000. Vol.67. No.3. P.387-389. (russian)

[36] M.Yu. Dolomatov, D.O. Shulyakovskaya, G.U. Yarmukhametova, G.R. Mukaeva. Evaluation of the physico-chemical properties of hydrocarbon systems by correlations of the spectrum-properties and color-properties. Chemistry and technology of fuels and oils. 2013. No.3. P.52-56. (russian)

[37] M.Yu. Dolomatov, G.U. Yarmukhametova, L.A. Dolomatova. The relationship of physico-chemical and color properties of hydrocarbon systems in colorimetric systems RGB and XYZ. Applied Physics. 2008. No.4. P.43-49. (russian)

[38] M.Yu. Dolomatov, G.U. Yarmukhametova. The relationship of color characteristics with coking ability and molecular weight of complex hydrocarbon media. Journal of Applied Spectroscopy. 2008. Vol.75. No.3. P.406-410. (russian)

[39] G.U. Yarmukhametova, M.Yu. Dolomatov. The calculation of the average molecular weight, coking ability and activation energy of a viscous flow of reservoir oil samples using color-properties correlations. Geology, geophysics and oil field development. 2009. No.7. P.35-37. (russian)

[40] M.Yu. Dolomatov, G.U. Yarmukhametova, D.O. Shulyakovskaya. Evaluation of the first ionization potentials and electron affinity of polycyclic organic semiconductors by color characteristics in colorimetric systems XYZ and RGB. Applied Physics. 2011. No.1. P.20-31. (russian)

[41] M.Yu. Dolomatov, D.O. Shulyakovskaya. Evaluation of the physicochemical properties of multicomponent hydrocarbon systems by the integral characteristics of electronic absorption spectra. Chemistry and Technology of Fuels and Oils. 2013. No.2. P.49-52. (russian)

[42] M.Yu. Dolomatov, D.O. Shulyakovskaya, R.S. Manapov. Possibility of determining relative density of lubricating oil fractions from photoimages. Chemistry and Technology of Fuels and Oils. 2015. Vol.56. No.5. P.829-835.

[43] M.Yu. Dolomatov, D.O. Shulyakovskaya, R.S. Manapov. On the possibility of determining the relative density of oil fractions from photographs. Chemistry technology fuels and oils. 2015. Vol.16. No.3. P.51-53. (russian) 